\title{
SOBRE PURISMO LINGÜÍSTICO EN LA PRENSA ESPAÑOLA DEL SIGLO XIX: EN TORNO A LA FIGURA DE A. DE CAPMANY
}

\author{
MARTA TORRES MARTÍNEZ \\ Universidad de Jaén*
}

Resumen

Tras la consulta de fuentes del siglo XIX en la Hemeroteca Digital de la Biblioteca Nacional de España, hemos hallado información relevante que gira, fundamentalmente, en torno a dos cuestiones: las ideas sobre purismo lingüístico insertas en las reseñas de numerosas publicaciones de la época -por ejemplo, a propósito de los Principios de lengua francesa para uso de los españoles (Valencia, 1815) de Luis Monfort- y los artículos de opinión que ven la luz ad hoc en relación con este tema -por ejemplo, las «reflexiones preliminares» al Diario de Madrid (núm. 32 de 7 de febrero de 1812) donde se indica que "aún no ha alzado cabeza nuestra lengua [...] se ha introducido un diluvio de voces y modismos de la lengua francesa, los quales a manera de un torrente han inundado nuestro idioma»-. Los dos ámbitos tienen, especialmente, su lugar de encuentro en la información documentada en la prensa decimonónica alrededor de la figura de Antonio de Capmany (Barcelona, 1742-Cádiz, 1813), que muestra una interesante evolución en lo que respecta, a su parecer, en torno al purismo lingüístico.

Palabras clave: purismo lingüístico, prensa española, siglo XIX, galicismos, Antonio de Capmany.

\section{LINGUISTIC PURITY IN THE SPANISH PRESS DURING THE $19^{\text {TH }}$ CENTURY: ABOUT THE FIGURE OF A. DE CAPMANY}

\footnotetext{
* Esta investigación se ha gestado en el marco del Proyecto Ideas lingüísticas y pedagógicas en la prensa del siglo XIX (PGC2018-098509-B-I00]), financiado por el Ministerio de Ciencia, Innovación y Universidades del Gobierno de España y dirigido por el Dr. Victoriano Gaviño Rodríguez (Universidad de Cádiz) y por la Dra. María José García Folgado (Universidad de Valencia).
} 
Abstract

After consulting $19^{\text {th }}$ Century sources in the Digital Newspaper Archive of the National Library of Spain, we have found relevant information about two issues: the ideas about linguistic purity inserted in the reviews of several publications of the era -e.g. regarding The Principles of the French Language for Spanish Speakers (Valencia, 1815) by Luis Monfortand opinion articles published ad hoc on this topic -e.g. the "preliminary reflections» about Diario de Madrid (no. 32 from the $7^{\text {th }}$ February 1812) where it indicates that «our language has not risen its head yet [...] several terms and idioms from the French language have been introduced, flooding our language as a torrent»-. Both issues have as a meeting point the documented information from the $19^{\text {th }}$ Century press about the figure of Antonio de Capmany (Barcelona, 1742-Cadiz, 1813), who presents his views on the interesting evolution of linguistic purity.

Key words: linguistic purity, Spanish press, $19^{\text {th }}$ Century, gallicisms, Antonio de Capmany.

\section{INTRODUCCIÓN}

Lázaro Carreter (1985: 259) caracteriza casticismo y purismo como «la fuerza activa surgida en la primera mitad del siglo XVIII, por acción de la Academia y del neoclasicismo, cuyo fin es resucitar el pasado lingüístico nacional» $\mathrm{y}$ «el rechazo a la intromisión de vocablos nuevos, procedentes de otras lenguas o de una creación personal», respectivamente.

La pureza de la lengua se suele entender en términos de homogeneidad, integridad y limpieza, esto es, en relación con la ausencia de faltas, solecismos o barbarismos. Así, en su estudio sobre la mentalidad purista en los siglos XVI y XVII mediante el análisis de imágenes y metáforas, Lescasse (2018: 108) recuerda el sintagma purismo xenofónico, acuñado por George Thomas y referido a la aversión a la llegada de voces extranjeras.

En este sentido, ya Ludwig (2000-2001: 168) caracterizó el purismo como «una actitud que surge como solución en una situación de contacto lingüístico cultural (en el sentido más amplio), situación que es vivida como problemática».

Nos interesa, en este trabajo, aproximarnos a las ideas que sobre el purismo lingüístico se localizan en la prensa decimonónica en relación, particularmente, con Antonio de Capmany. 


\section{PURISMO LINGÜÍSTICO EN PRENSA DECIMONÓNICA}

Es interesante destacar cómo, de un lado, hemos encontrado documentos de interés como, por ejemplo, las «reflexiones preliminares» al "Anuncio de un plan de la lengua castellana», publicado en el Diario de Madrid (núm. 32 de 7 de febrero de 1812) y motivado precisamente por «el diluvio de voces y modismos de la lengua francesa, los quales a manera de un torrente han inundado nuestro idioma», en el que se indican ítems léxicos procedentes del francés que hay que evitar y sustituir por voces disponibles en español (entre otros, conocedores por inteligentes, decapitar por degollar, golpe de vista por ojeada, habitud por hábito o costumbre o muestra por reloj). En el final de este plan ${ }^{1}$, publicado dos números más adelante, en el Diario de Madrid (núm. 32 de 7 de febrero de 1812), se vuelve a insistir sobre el peligro de la corrupción lingüística, pues «con ocasión de nuestro trato y conversación con los franceses no puede ser menos sino que se introduzcan y domicilien sin necesidad entre nosotros muchas voces y locuciones de la lengua francesa».

De otro lado, hemos localizado algunas ideas insertas en las reseñas de numerosas publicaciones de la época. Por ejemplo, a propósito de los Principios de lengua francesa para uso de los españoles (Valencia, 1815) ${ }^{2}$ de Luis Monfort -obra que consta de una parte teórica y otra práctica: en la primera se describen los fundamentos gramaticales del francés, mientras que en la segunda se ofrecen ya aplicados en la lectura, traducción y escritura (Pastor, 1830: 510)-, en Crónica Científica y Literaria (núm. 133 de 7 de julio de 1818) se advierte que, si bien el autor plantea ideas útiles sobre la traducción y muestra un gran manejo al resolver equivalencias entre ambas lenguas, sus ideas no van a poder ser adoptadas por «una excesiva timidez o purismo». Vemos pues cómo, en la prensa española

\footnotetext{
${ }^{1}$ Este plan de la enseñanza de la lengua castellana gira en torno a tres principios: (i) «manifestar el número, usos y quanto pertenece a las partes de la oración», (ii) «tratar de la sintaxis con extensión» y «la ortografía y la etimología de la mayor parte de las voces, advirtiendo que quando se trate de la sintaxis, se confirme la doctrina tocante a ella con exemplos tomados del Quixote de Cervantes».

${ }^{2}$ En Alvar Ezquerra (2020) se indica que, en el interior de los Principios de lengua francesa, Monfort puso una nomenclatura bajo el encabezamiento de «Traducción española-francesa» en la que sigue Arte de hablar bien francés (editado por vez primera en 1781) de Pierre Nicolas Chantreau (1741-1808).
} 
generada en el primer cuarto del siglo XIX, existe una postura claramente negativa ante la influencia de la lengua del país vecino.

Hemos localizado también una «correspondencia entre un doctorcito flamante y su padre», a propósito del neologismo, publicada en la Gaceta diaria de México (núms. 65 y 66 de 6 y 7 de marzo de 1826). En estas cartas, el «doctorcito flamante» alude a voces como chargé d'affaires, roast bee $\beta^{\beta}$ o fricandeau ${ }^{4}$ y su interlocutor, el padre, le recrimina este uso -aunque no se considera purista "o de los que hablan de fijar el idioma», pues le «expone al ridículo». No obstante, el hijo defiende el uso y el hecho de que «las palabras vienen a ser viejas como las personas y se reponen con otras nuevas», si bien el padre le aconseja que no se aflija ni tema por «la pobreza del castellano» porque «cada lengua tiene su abundancia». Las ideas contenidas en este cruce de misivas muestran las preocupaciones en torno a la lengua durante la segunda mitad del siglo XVIII y el XIX, centradas en dos cuestiones: las traducciones y los galicismos.

En lo que respecta a la traducción, parece que predominó una actitud positiva durante el siglo XVIII (Checa, 1991: 594; Anglada, 1997-1998: 32). Posteriormente, según Checa (1991: 595), la escasa preparación de los individuos que realizaban las traducciones motivó que se entendiera como «un modo de corrupción de nuestra lengua». Se aducían problemas como la índole de las traducciones, innecesariamente pegadas a la lengua de origen, o la falta de instrumentos a la hora de documentarse como, por ejemplo, la escasez de diccionarios donde consultar las voces nuevas que necesitaban traducirse.

Además, sin duda, el cambio de signo se vio favorecido por las circunstancias políticas en las que se encontraba España, inmersa en el período napoleónico (1808-1813) y rebelada contra la ocupación francesa.

${ }^{3}$ Como indicamos en Torres (en prensa), en las Apuntaciones idiomáticas y correcciones de lenguaje (1943) de Roberto Restrepo se indica que «la carne de vaca soasada tiene ya su nombre en el diccionario, rosbif, un poco rudo para nuestro armonioso idioma, pero menos bárbaro en su escritura que el roastbeef que usan los elegantes». En efecto, rosbif se lematiza en la tradición lexicográfica del español a partir del Diccionario de la lengua castellana (1884) de la RAE: "del inglés rostbeef. Carne de vaca soasada».

${ }^{4}$ Fricandeau se recoge en el Diccionario general de cocina (1892) de Ángel Muro como «carne de ternera mechada de una manera especial y cocida en su jugo, que sirve para entrada». La variante fricandó se documenta en la tradición lexicográfica del español desde el Diccionario castellano (1786-93[1767]) de Terreros, "voz tomada del fr. cierto guisado de ternera o vaca a modo de estofado». 
Esta cuestión enfrentaba, de un lado, a los partidarios de la apertura hacia el progreso y a la libertad en el ejercicio de la traducción ${ }^{5}$, idea representada, entre otros, por Feijóo y Mayans, y, de otro lado, a los defensores de la pureza del castellano, apoyada por Forner y Vargas Ponce ${ }^{6}$.

\section{ANTONIO DE CAPMANY Y EL PURISMO LINGÜÍSTICO}

\subsection{Antonio de Capmany y su obra}

Los dos ámbitos citados más arriba -traducción y galicismos- tienen, especialmente, su lugar de encuentro en la información documentada en la prensa decimonónica alrededor de la figura de Antonio de Capmany (Barcelona, 1742-Cádiz, 1813). En el Diccionario histórico de la traducción en España (Lafarga y Pegenaute, 2009: 173-174) se da noticia de la vida de este autor:

Escritor español. Optó primero por la carrera militar, que abandonó en 1770; se trasladó a Sevilla, donde colaboró con Olavide para llevar colonos catalanes a Sierra Morena. En 1775, anticipando la caída del intendente, marchó a Madrid. Este mismo año, consiguió ingresar en la Academia de la Historia y, en 1790, fue elegido secretario perpetuo, cargo que desempeñó hasta 1802. Publicó varios trabajos sobre la Barcelona medieval y su actividad marítima, considerados como pioneros en la historia económica española. Además, reveló sus dotes de filólogo en obras relacionadas con la lexicografía, la retórica (Filosofía de la elocuencia, 1777 y 1812) y la historia literaria (Teatro histórico-crítico de la elocuencia española, 1786-1794). Durante la Guerra de la Independencia se señaló por un extremado patriotismo que ilustra su Centinela contra los franceses (1808). A finales de 1808 se refugió en Sevilla y trabajó en la preparación

${ }^{5}$ Según Checa (1991: 596): «La necesidad, lógica, de tomarse 'licencias' en la traducción, ocasionó una serie de novedades, desvíos o malformaciones en el castellano que afectaban a su léxico, sintaxis o estilo, pero, sobre todo, la influencia más polémica fue la referida a la creación de palabras nuevas».

${ }^{6}$ En definitiva, como señala Vidal (2011: 408), «dos son las posturas que se contraponen: la de los puristas, celosos defensores de la pureza de la lengua, frente a los innovadores que reclaman el derecho a introducir nuevas voces que respondan a nuevas necesidades expresivas de una sociedad que evoluciona con rapidez». 
de las Cortes de Cádiz, en las cuales actuó como diputado por Cataluña hasta su muerte ${ }^{7}$.

Entre sus obras, además de sus repertorios lexicográficos bilingües, destacamos el Arte de traducir el idioma francés al castellano (1776), que conoce una segunda edición en 1839 de la mano de Antonio Alcalá Galiano y Vicente Salvá, "cuyo objetivo fue el de combatir los idiotismos de la lengua francesa presentes en las traducciones castellanas de su tiempo» (Yllera y Ozaeta, 2002: 84). Como apunta Checa (1989: 135-136): «aunque no enfatiza ya las imperfecciones del español como hacían los Discursos analíticos, en su Arte de traducir trasluce todavía una actitud bastante favorable para con la lengua francesa» ${ }^{8}$. En el prólogo a esta obra, Capmany (1776: VI) declara que «una traducción será imperfecta siempre que con ella no podamos conocer y examinar el carácter de la Nación por el del autor». Además, muestra indulgencia por las voces y usos galos, si bien indica que «algunas de estas voces, que caracterizan el idiotismo francés, se han de suprimir, otras substituir y otras acompanar con partículas, conjunciones o rodeos auxiliares, que exige el genio de la lengua española»(Capmany, 1776: XIII) .

No obstante, Capmany refleja el paso de una actitud a otra. Como señalan Checa (1991: 598-599) y Cazorla (2002: 19), mientras que en sus primeras obras alaba la lengua francesa y se muestra favorable a las traducciones del francés, en su Teatro histórico-crítico de la elocuencia española (1786-1794), una antología de modelos de elocución, deriva hacia

${ }^{7}$ También, al realizar la semblanza biobibliográfica de Capmany, Cazorla (2002: 358360) afirma que «entre sus detractores destacan dos nombres conocidos, el escritor Manuel José Quintana, con el que tuvo públicas disputas, y por otra, el gran lexicógrafo Vicente Salvá».

${ }^{8}$ Como señalan Hériz y San Vicente (2012: 212), el predominio arrollador del francés como lengua de origen de la mediación explica el auge espectacular de la lexicografía hispano-francesa decimonónica y el hecho de que los dos diccionarios bilingües que más éxito tuvieron fueran el de Capmany de 1805 y el de Núñez de Taboada de 1812. Además, también aluden a las varias reimpresiones de El arte de traducir el idioma francés al castellano de Capmany.

${ }^{9}$ Vemos cómo, a juicio de Crespo (2008: 18), en este momento, «Capmany, partidario de las buenas traducciones como vehículo para conocer lo que se pensaba y hacía fuera de las fronteras patrias, se aplicó a lo que consideró estrechamente relacionado con la visión del mundo y cada idioma». 
una postura totalmente opuesta ${ }^{10}$, pues achaca el empobrecimiento del español a las malas traducciones que se hacían. También Lázaro (1949: 264) se hace eco del cambio radical de las ideas de Capmany: «de la amplitud máxima en la aceptación de vocablos extranjeros, a la mayor estrechez, al purismo más cerrado». De hecho, en opinión de Capmany, nuestra lengua no tenía necesidad de ser auxiliada por el francés a la hora de nutrir y ennoblecer su léxico, ya que podía autoabastecerse o, en todo caso, ser asistida por las lenguas clásicas.

En este sentido, a juicio de Martinell (1984: 105-106), el afrancesamiento de la lengua, como el de otras manifestaciones, es duramente atacado por este autor. No obstante, esta investigadora no cree que el modelo francés decayera alrededor de 1808, aunque en la obra de Antonio Capmany Centinela contra franceses campea una exaltación patriótica y un enorme desprecio por lo francés debido a que «el estallido de la Revolución Francesa debilitó los entusiasmos de más de un afrancesado» ${ }^{11}$.

Lo cierto es que, según Martinell (1984: 109), la palabra purista $^{12}$ se aplica a los que manifiestan un celo excesivo en la observancia y defensa de la pureza de la lengua: «la corrección y exactitud son cualidades constitutivas de la pureza del lenguaje... No hemos de confundir la pureza del lenguaje con el purismo: afectación minuciosa, que estrecha y aprisiona

${ }^{10}$ Por ejemplo, en el prólogo al tomo IV del Teatro histórico-crítico, Capmany (1788: 4), tras aludir a los trabajos de Bernardo de Aldrete, Sebastián de Covarrubias, Ambrosio de Salazar o Jiménez Patón, afirma que «ni la lengua no la eloqüencia cogieron fruto alguno de los desvelos de estos buenos patriotas porque la enfermedad, aunque oculta, era ya incurable; las costumbres caminaban hacia otro rumbo y las ideas, por consiguiente, iban a tomar otra forma, y lo peor de todo era que muchos de los que querían corregir el mal estaban, sin sentirlo ellos, contagiados en gran parte».

${ }^{11}$ Destacamos un párrafo donde Capmany (1808: 72) muestra su aversión a lo francés: «hoy, que con la inundación de libros, estilos y modas francesas se ha afeminado aquella severidad española, llevando por otra senda sus costumbres [...] hoy que ni se leen nuestras historias, ni nuestras comedias, ni nuestros romances y jácaras, tratándolo todo de barbarie e ignorancia; hoy que es moda, gala, y buena crianza celebrar todo lo que viene del otro lado de los pirineos y olvidar afectadamente todo lo que huele a nuestro suelo hasta despreciar lo que la naturaleza nos ha dispensado tan generosamente».

12 Álvarez de Miranda (2013) sitúa el nacimiento del purismo y de la palabra misma que lo designa en el siglo XVIII: «en la lengua del país vecino puriste se documenta desde 1625 y purisme desde 1701. En la nuestra es Feijoo quien en 1742 empleó por vez primera purista [...] puede aceptarse como primera datación válida de purismo la presencia de la voz en el repertorio de Terreros, terminado en 1767. El jesuita la define como «modo de hablar con pureza y correctamente», pero añade: «también lo toman algunos por el modo de hablar afectado»». 
el ingenio» (Antonio de Capmany, Filosofía de la eloquencia, 1777, pág. $40)^{13}$.

Checa (1988: 89) compara, precisamente, las dos ediciones de esta última obra citada, Filosofía de la elocuencia (1777 y 1812), y detecta que, en la segunda edición, se suprimen dos párrafos en los que Capmany atacaba el purismo ( «afectación minuciosa que estrecha y aprisiona el ingenio»). Este investigador apunta que el catalán se declara purista: «en este cuidado no hallo nimiedad por más que ladren los antipuristas ${ }^{14}$.

Por su parte, Jiménez Ríos (2015: 50-51) apunta que Capmany considera, en sus primeras obras, que todos los purismos son fríos, secos y descarnados y se muestra, y, en consecuencia, se muestra su obra Discursos analíticos partidario de voces nuevas «para hermosear la lengua».

\subsection{Ideas de Capmany en torno al purismo lingüístico en prensa decimo- nónica}

A continuación, revisamos la prensa del siglo XIX a fin de localizar ideas relativas al purismo lingüístico en torno a la figura de Capmany y su obra.

A propósito de la publicación del Nuevo diccionario francés-español (1805), en el Memorial literario. Biblioteca periódica de ciencias y artes (núm. 27, de 30 de septiembre de 1805) ve la luz una reseña en la que se destaca su «distinguido mérito y feliz desempeño» debido a que «el que se atreve a semejante empresa es un sugeto de luces» y ha demostrado

${ }^{13}$ Es un poco difícil saber si todos entienden lo mismo por "pureza de la lengua» ya que en los textos a veces se alude a una lengua imitadora de gloriosos momentos (desde luego, se refieren a momentos literarios), pero otras veces se alude a una lengua limpia de extranjerismos, a la vez que recuerdos barroquizantes. En general los que opinan que la pureza de la lengua es una cualidad ya establecida creen que la lengua de su época está perdiéndola: «Esta, digámosla fascinación, ha cundido con tanto poder, que ha logrado resfriar el amor a nuestra propia lengua, cuya pureza y hermosura hemos manchado con voces bárbaras y espurias» (Antonio de Capmany, Teatro histórico-crítico de la eloquencia española, 1776-1791, tomo I, Discurso preliminar, CXXXVII) (Martinell, 1984: 109).

${ }^{14}$ De hecho, Checa (1988: 90) concluye que «el Capmany de los primeros escritos filológicos se mostraba como un admirador de Francia, de su lengua, sus autores y su cultura [...] En los años ochenta se muestra como un autor moderado [...] con el nuevo siglo, el autor catalán decide presentarse públicamente como un patriota radical, nacionalista extremo que repudia a Francia». 
«una posesión exquisita de ambos idiomas, un conocimiento muy particular de la índole del nuestro, un estudio muy filosófico de nuestras frases familiares, que tantas relaciones guardan con nuestras costumbres, una continua práctica de comparaciones y en fin una meditación intensa» ${ }^{15}$.

A diferencia de los repertorios que lo precedieron, como destaca Bruña (1999: 99), este diccionario no se concibe como «un instrumento apto para ayudar a los que quieren aprender francés, sino, principalmente, como una herramienta de base para quienes emprendían una traducción del francés al español».

Se trata de un repertorio unidireccional francés-español, pues el propio autor en el prólogo manifiesta el fracaso que experimentaría la elaboración de la parte español-francés ante la dificultad de traducir numerosos vocablos al francés (a pesar de que años más tarde el diccionario quedaría completo con esta otra parte, como veremos más adelante). En definitiva, Capmany (1805: I) reconoce los seis años de «lucha metafísica de carear y ajustar dos lenguas tan discordes entre sí», trabajo que inicia a fin de paliar el panorama de la lexicografía bilingüe francés-español para no «mendigar más tiempo de manos extrangeras» (Capmany, 1805: II).

En la extensa reseña hallada se alaba continuamente la labor de Capmany, especialmente «el inmenso trabajo que debe haber costado el buscar unas correspondencias justas, y legítimamente españolas, a los modismos y expresiones vulgares del francés» (págs. 383-384) ${ }^{16}$. Además, se alude a los repertorios de Gattel y Cormon, publicados en el siglo anterior (1790 y 1769, respectivamente), citados varias veces por Capmany

${ }^{15}$ No en vano, a propósito de Capmany, ya Lázaro (1949: 280) señala que «por primera vez, un español se impone la tarea seria y científica de comparar ambas lenguas [español y francés], intentando hallar una justa correspondencia, cuando se trata de palabras patrimoniales, o fijando una norma que corresponda al tecnicismo francés».

${ }^{16}$ En efecto, en cuanto a la metodología seguida, el catalán insiste en que en la formación del presente diccionario «no solo se ha trabajado con tesón para que a cada voz francesa correspondiese la genuina española, huyendo de las explicaciones vagas o insignificativas, sino que, a costa de un extremado esmero, se ha procurado conservar en la correspondencia castellana el mismo sentido en que se toma, y el mismo estilo en que se usa la palabra francesa [...] He puesto la diligencia y esmero más riguroso a fin de que cada artículo pueda servir de regla al lector»(Capmany 1805: VIII-IX). 
en su prólogo para dejar constancia de sus errores e imprecisiones ${ }^{17}$. Una de las características del repertorio que se celebra es el abundante número de correspondencias, "pues en diversos casos se acomodan mejor unas frases que otras y así se evita el que nuestros traductores inexpertos se deslicen en absurdos monstruosos, como se deslizaban antes por fiarse a los miserables Diccionarios de que se valían para sus traducciones" (pág. 388). Más adelante se habla de una obra en elaboración, el Diccionario comparado de la lengua francesa y española, proyectado por Capmany a fin de «socorrer a los traductores con una llave maestra» en materia de fraseología ${ }^{18}$.

De otro lado, hemos localizado sendas misivas entre Capmany y un anónimo lector, publicadas en Nuevas efemérides de España, históricas y literarias (27 de septiembre de 1805) y en Memorial literario. Biblioteca periódica de ciencias y artes (núm. 27 y 30, de 30 de septiembre y 30 de octubre de 1805, respectivamente), a propósito del artículo relativo a la voz orfebre, incluido en su Nuevo diccionario francés-español(1805).

Orfevre. s. m. Platero: artífica que trabaja en plata y oro.

El corrector anónimo indicaba que este ítem léxico de origen francés tiene dos equivalencias en nuestra lengua: «quando se quiere significar con ella el artífice que trabaja muebles (alhajas o piedras se querrá decir) de plata se traduce por platero y quando se ha de aplicar al que lo hace de oro, tenemos las palabras orespe y orero, usadas por nuestros mejores autores».

En cuanto a las autoridades que aporta para sancionar el uso de esta palabra, cita dos, Quilatador de oro, plata y piedras (1678) de Juan Arphe de Villafañe y el Diccionario castellano (1786-93[1767]) de Terreros, así como «los rótulos de las tiendas de la calle Carretas».

En el caso de orespe, comprobamos cómo se recoge desde el Diccionario de autoridades (1726-39), con el significado de 'platero y artífice

${ }^{17}$ De este modo «se desengañó de que era casi inasequible la refundición de tan repetidos absurdos y así determinó formar enteramente un Diccionario nuevo y olvidarse de los que hasta ahora teníamos para no confundirse en el caos de sus disparates» (págs. 384-385).

${ }^{18}$ Según manifiesta el firmante de la reseña -cuyas iniciales son A. C-, «tal vez con el auxilio de dicha obra, los malos traductores no continuarán corrompiendo nuestra lengua tan deplorablemente como hasta ahora». 
que trabaja en cosas de oro, que es donde se forma' -si bien se incluye, tras la definición, una paráfrasis de índole cronológica («es voz antiquada»)-, y se documenta a lo largo de la tradición lexicográfica académica y extraacadémica. No obstante, no hallamos ningún registro de esta voz en CORDE.

Orero se registra por vez primera en el Diccionario castellano (178693[1767]) de Terreros, caracterizada como 'voz burlesca, platero de oro' y documentada en La Pícara Justina. Cabe destacar que en el NTLLE, orero solo se incluye en otros cinco repertorios: Nuevo diccionario de la lengua castellana (1846) de Salvá ('capr. Orífice') -voz marcada al inicio de su artículo por una cruz, que indica que todo el artículo "se ha aumentado», según advierte en el prólogo el mismo Salvá. No obstante, la abreviatura capr. significa 'voz caprichosa de algún escritor clásico'-; Diccionario nacional o Gran diccionario clásico de la lengua española (1853[1846-47]) de Domínguez ('inus. El que trabaja en oro'); Diccionario enciclopédico de la lengua española (1853-55) de Gaspar y Roig ('adj. s. inus. Orífice'); Nuevo suplemento al Diccionario nacional o Gran diccionario clásico de la lengua española (1869) de Domínguez ('s. m. capr. Orífice') y Diccionario enciclopédico de la lengua castellana (1895) de Zerolo ('m. El que trabaja en oro'). Podemos comprobar cómo el único repertorio que considera orero como voz general es este último. No obstante, tras consultar CORDE, hemos localizado únicamente un solo registro, el incluido en Terreros, a saber, La Pícara Justina (1605) de Francisco López de Úbeda («por relucir que vea las cosas, no piense que son oro, aunque se lo diga un platero de oro o un orero de plata, que de bajo de un bolsito de tela hay mil telas y mil engaños»).

También hemos consultado estas dos voces en el Fichero General de la RAE, que arroja 12 resultados en el caso de orero y solo 3 para orespe.

Orero se documenta, igualmente, en La Pícara Justina y es recuperada por F. Burgos en Cuentos (1925), según la cédula firmada por Ignacio Soldevila y marcada con Arg Andina («nadie sino el orero sabe lo que cuesta encontrar una pepita de oro», p. 70). Además, se documenta en Chilenismos (1928) de J. T. Medina ('m. Partidario de la moneda de oro, en contraposición a la de papel'), en el Atlas Linguḯstico y etnográfico de Aragón, Navarra y La Rioja (1978-83), de Manuel Alvar con la colaboración de Antonio Llorente, Tomás Buesa y Elena Alvar ('as de oros'), en el 
Vocabulario navarro (1952-84) de Iribarren y Ollaquindia ('nombre que dan al as de oros' [Pamplona, Urraúl-Bajo]) y en el Vocabulario de ocupaciones (1963) del Ministerio de Trabajo ('el que busca hojuelas de oro en las arenas de los ríos'). Observamos, pues, cómo esta voz se ha reinventado y se ha especializado diatópica y diastráticamente, tal como se documenta a lo largo del siglo XX.

Orespe, por su parte, se cita en el tomo 11 (pág. 322) de El lenguaje (1901-12) de Julio Cejador, en el Diccionario del lenguaje antiguo casteIlano (a. 1833) de Ramón Cabrera ('s. m. Platero o artífice que trabaja en cosas de oro') y en el Diccionario de uso del español (1966-67) de María Moliner ['(ant.) Orebce. Orífice’].

A las observaciones realizadas por el anónimo lector, Capmany contesta en el Memorial literario. Biblioteca periódica de ciencias y artes (núm. 28, de 10 de octubre de 1805). El autor reconoce que el artículo "es pequeño en su extensión, mas no en la intensión con que se trabajó» (págs. 34-35). En cuanto a la voz orespe, reconoce haberla leído en «libros antiguos y ordenanzas gremiales», si bien declara: «considerándola como antiquada, la omití, pareciéndome una afectación usarla» (pág. 35). En lo que respecta a orero, indica lo que sigue: «no la he leydo, ni oído jamás; ni tampoco está en el diccionario de la lengua castellana». Capmany, además, avisa al lector anónimo de que también existen los ítems orífice y oribe, a las que no se refiere en su carta, si bien se encuentran en desuso, al igual que orespe. Capmany cree que «se haría ridículo el que tomase dichas voces como corrientes y usuales» (pág. 35), pues entiende que, además de obsoletas, son palabras adscritas a un ámbito de especialidad muy concreto.

No obstante, Capmany agradece a su interlocutor la advertencia, «hija, como se trasluce, de amor patriótico a nuestra lengua» (pág. 37) y anima a la ciudadanía a que siga haciendo observaciones a su diccionario, al tiempo que deja constancia del detallado y arduo trabajo previo a la redacción de los diferentes artículos que conforman un diccionario: «sobre cada uno he hecho preliminares estudios y pruebas, de que el lector no ve más que el resultado simple y limpio en el impreso» (pág. 38).

A Capmany el lector anónimo le contesta en el Memorial literario. Biblioteca periódica de ciencias y artes (núm. 30, de 30 de octubre de 1805) $\mathrm{y}$, al inicio de su carta, habla de su primer opúsculo, «una cosuela escrita 
con precipitación y sin cuidado» (pág. 127). No obstante, le recrimina no haber reparado en las veces que se puede leer bijoutier, o platero de oro en los establecimientos de la calle Carretas. Además, reconoce no haber citado las voces oribe y orífice, pues alega que su carta «no fue una censura premeditada, ni una disertación académica sobre estas palabras, sino un simple aviso literario dado con la mejor buena fe del universo». Tras estas palabras, le recrimina a Capmany, a su vez, que él tampoco ha reparado en otros dos ítems: orfebre y orero. La primera la documenta en Juan Arphe de Villafañe, «en quien cabe sospecha de galicismo» (pág. 129) ${ }^{19}$.

También alude a la inclusión en el Diccionario de la RAE de «las palabras orificia y orfebrería por el arte de trabajar piezas de oro, orífice por el artista que lo executa y orespe con la misma significación» (pág. 129).

Seguidamente discute la siguiente afirmación realizada por Capmany en su carta:

Todas estas voces, vuelvo a decir, las tuve presentes, y las examiné, combiné y deseché antes de extender el breve artículo de orfebre, que no pasa de línea y media, en cuya reducida explicación de la recta correspondencia castellana platero, se incluyen los dos géneros de metal en que trabaja y puede trabajar indistintamente el artífice. Solo hay la diferencia, no el uso, sino en la etimología, de que en francés la voz toma la denominación genérica del metal más precioso, que es el oro; y en español del metal inferior, que es la plata, sin que en uno y otro país formen arte o industria distinta. Solo quando alguno se dedica particularmente a alhajas y dixes de oro y pedrería, le llamamos comúnmente platero de oro; así se intitulan

${ }^{19} \mathrm{Al}$ consultar el NTLLE, observamos que orfebre se documenta por vez en el Nuevo diccionario de la lengua castellana (1846) de Salvá («m. ant. El artífice que trabaja en plata y oro»). Zerolo en su Diccionario enciclopédico de la lengua castellana (1895) aporta notas acerca de su etimología: «m. Orífice. Esta palabra, tomada del francés orfebre, la hemos visto usada modernamente con frecuencia». La primera edición del repertorio académica que incluye orfebre es el $D R A E$ (1899): "(Del lat. auri faber, artífice de oro) m. Artífice que trabaja en orfebrería». Esta etimología se mantiene hasta el DRAE (1984), donde se especifica: «(Del lat. auri faber, artífice de oro, a través del fr. orfevre)». En la vigente edición del diccionario académico encontramos dos acepciones y una etimología precisa: «Del fr. orfèvre. 1. m. y f. Persona que labra objetos artísticos de oro, plata y otros metales preciosos, o aleaciones de ellos. 2. m. y f. Col. Persona que labra objetos artísticos de cobre u otros metales». 
ellos mismos y así los nombran las ordenanzas del cuerpo de plateros. Yo bien quisiera llamarlos orespes, orífices u oribes [...] (pág. 36).

$\mathrm{Al}$ anónimo lector no le parece que orfebre comprenda las voces platero y orespe, "pues el francés con sola una palabra señala las dos cosas, y no dice orfebre en argent, como nosotros platero de oro, que es un despropósito». Y, en ese sentido, cuestiona a Capmany "¿cómo distinguirá un traductor del latín el aurifex y argentifaber, del alemán el Golds-arbeiter y el Silber-arbeiter, del inglés el Goldsmith y el Silbers-mith y el italiano la orificheria de la argenteria si según vmd. dice no hay más equivalente que platero?». Por tanto, insiste en que Capmany debía haber adoptado algunas de las voces españolas orespe, oribe, orífice, orfebre y aun orero, «tanto más quando en su prólogo declara vmd. que no ha tenido reparo en usar algunas libertades siempre que ha hallado conveniencia en ello» (pág. 131).

Al despedirse, el lector desconocido jura «por el amor a las disputas útiles» no volver a responderle al autor del diccionario, así como no «comunicarle algún otro pecadillo», pues se declara «amigo de sus talentos».

De otra parte, el Diario de Madrid (núm. 263 de 20 de septiembre de 1814) anuncia la publicación de una nueva edición de su Diccionario francés-español y español-francés (París, 1812), en la que se incorpora «la parte española-francesa, no menos importante, y en la que nuestro hermoso idioma ostenta su riqueza y superabundancia».

A pesar de que los editores señalan «el mérito real del Diccionario del señor Capmany» se indican algunas cuestiones a rectificar como "corregir las definiciones y faltas de correspondencia de muchas voces facultativas, añadir otras y un crecido número de términos omitidos» $\mathrm{O}$ «enmendar las innumerables invenciones y faltas de ortografía de el poco cuidado del impresor ha dexado salpicada esta obra». Al final de la publicación se advierte que esta obra es «poco conocida en España y mui apreciada fuera de ella».

En torno a la fecha de 1812, hemos registrado la noticia de la segunda edición de Filosofía de la elocuencia, «executada en Londres, se vende en Cádiz en la librería de Carsí calle Ancha, frente de los Gremios» (El 
Conciso de Cádiz, núm. 25, de 25 de diciembre de 1812, pág. 8) ${ }^{20}$, así como de dos noticias relativas al ámbito político referidas a la exposición pública que Capmany realizó en las Cortes en septiembre de $1812^{21}$. Al consultar los registros del año 1813, solo hallamos una noticia relativa a su fallecimiento: «Ha muerto después de una larga y penosa enfermedad con varias recaídas, el literato D. Antonio Capmany, Diputado por Cataluña en las Cortes Extraordinarias»(El Patriota, núm. 42, 24 de noviembre de 1813, pág. 400).

Ya pasado el primer cuarto del siglo XIX, encontramos en la prensa referencias a Capmany a propósito de comentarios léxicos. Por ejemplo, en el Registro oficial del Gobierno de los Estados Unidos Mexicanos (núm. 94, de 31 de julio de 1831), se alude a algunas palabras que han sido «condenadas generalmente como espurias no lo siendo y que están autorizadas en el código inmortal de nuestra lengua (el Quijote) y en otros escritos no menos respetables de autores famosos» (pág. 366). Se alude a expresiones documentadas ya en la obra de Cervantes como, por ejemplo, yo soy contento de -«no ha de creerse sea francesismo por la

${ }^{20}$ A propósito de esta y otras obras de Capmany (como el Teatro crítico de la elocuencia española), años después de su fallecimiento, hallamos información en El correo: periódico literario y mercantil (núm. 331, de 23 de agosto de 1830) reclamando su reimpresión, debido a que "no es ahora el gusto dominante el de las obras clásicas y de sólida ilustración, sino el de la frivolidad; y en prueba de ellos no hay más que leer los anuncios de los libros que se publican, y se verá que la mayor parte son para entretener el ocio, y el resto compendios, manuales y diccionarios de todas clases, que proporcionan una tintura superficial de literatura, ciencias y artes, y a donde se va a beber a medida que se necesita, sin tener el trabajo de haber estudiado mucho para saber poco» (p. 4). A mitad del siglo XIX, seguimos documentando la impresión de su Filosofía de la elocuencia en El español (núm. 569, de 10 de mayo de 1846) e incluso se recoge como libro recomendado en la Facultad de Teología, en concreto para la materia de Oratoria sagrada ( $E I$ Católico, núm. 2330, de 12 de septiembre de 1846).

${ }^{21}$ De un lado, el anuncio del impreso de la Exposición preparatoria [sic] de D. Antonio de Capmany, «La patria perece si se tolera por más tiempo en su seno a los que fueron de un modo $u$ otro sus verdugos $=$ Exhorta al Congreso a que purifique el suelo y entresuelo de Madrid con el castigo de todos los malvados, eclesiásticos o seglares, por ser justifica que reclaman las víctimas de sus iniquidades» (El Conciso de Cádiz, núm. 11, de 11 de septiembre de 1812, pág. 7). De otro lado, la noticia de la misma publicación en otro diario: «Exposición patriótica que hizo Don Antonio Capmany, diputado en Cortes, en la sesión pública de 4 de setiembre de 1812 antes de abrirse la discusión sobre la minuta de decreto contra los que han servido al gobierno intruso. Se hallará en la librería de Castillo, frente a las gradas de san Felipe: en la de Sancha, calle de la Concepción gerónima, y en la de Quiroga, calle de las Carretas, junto a la plazuela del Ángel» (Diario de Madrid, núm. 265, de 22 se septiembre de 1812, pág. 339). 
traducción bastarda que se ha hecho de je suis content» (pág. 366)-, estaba en su mismo parecer-"y los franceses generalmente escriben il était de même avis, que es casi una traducción literal» (pág. 367)- o conocimiento - "no debe emplearse por noticias o especies», si bien en El Quijote se usa con el significado de idea o noticia (pág. 367)-.

Se indica, en definitiva, "cuan cautos debemos de ser en esto de calificar de galicismos muchas locuciones y palabras españolas de uso corriente o anticuadas porque nos suenan a francesas» (pág. 367). Y, en este punto, se alude a Capmany:

El mismo Dr. Capmany, escrupuloso y purísimo escritor de la lengua castellana, que conocía perfectamente, confiesa con lisura haberse equivocado en tomar por de su idioma lo que no era sino francés. Si esto dice un sabio, ¿qué diremos nosotros que no lo somos? Pero a lo menos poseemos la virtud de imitarle en hacer esta confesión que ya hicimos y que los remilgados pedantes semi-instruidos en la lengua no quieren o no pueden hacer ese sacrificio a la verdad.

Por último, queremos destacar que, a mitad de siglo, en el Seminario pintoresco español (núm. 17, de 25 de abril de 1847) se publica una biografía de Antonio de Capmany firmada por Gavino Tejado ( Apuntes biográficos y bibliográficos sobre el literato español D. Antonio Capmany y sobre algunas de sus obras poco conocidas e inéditas», págs. 131-134). En ella se narra cómo al autor, oriundo de una antigua y noble familia de Gerona, «el gobierno le confirió una comisión real para organizar la colonia de la Carolina que se fundó en aquellos tiempos, bajo la dirección del superintendente D. Pablo de Olavide». En cuanto a su obra, se detalla que «el objetivo invariable de todos sus trabajos y el norte de todos sus esfuerzos fue siempre vindicar a la patria sus preocupaciones extranjeras, evitar la degeneración de la lengua castellana, deplorar la desaparición de nuestras antiguas usanzas y oponerse a la importación de costumbres extranjeras» (pág. 132). Al comentar sus obras, realiza algunas indicaciones relevantes como las que siguen: «si los que se dedican a traducir hubiesen empezado por estudiar esta obra de Capmany, quizás no veríamos la lengua castellana en el deplorable estado a que la han reducido las versiones del francés que avergüenzan nuestra literatura» (pág. 133). 
En 1854, hallamos otra biografía de Capmany, publicada esta vez en La España (núm. 1913, de 25 de junio de 1854). Tras listar sus obras, se alude a su patriotismo, especialmente demostrado a raíz de la publicación de Centinela contra franceses, que «le distinguió de una manera particular». En esta semblanza, incluso se menciona un defecto del catalán, «la falta de facilidad en hablar o más bien en pronunciar», lo que no impidió que escribiera discursos en los que proponía, por ejemplo el 29 de septiembre de 1810, que «ningún diputado pueda solicitar ni admitir para sí ni para otra persona empleo, pensión, gracia, merced y condecoración alguna». En el mismo número se publica la noticia del traslado de los restos de Capmany de Cádiz a Barcelona, concretamente a la iglesia de Santa Mónica, «en una lindísima urna negra, con adornos de oro, coronada por una elegante cruz, sostenida por cuatro dorados pies de león y con dos planchas de plata, en la una de las cuales están grabadas las armas de Cádiz y en la otra las de Barcelona».

\section{FINAL}

En este estudio nos ha interesado revisar las ideas lingüísticas documentadas en la prensa del siglo XIX en torno a cuestiones como la introducción de nuevas voces -especialmente, galicismos-, a propósito de las traducciones llevadas a cabo en la época, o conceptos como el purismo. En definitiva, teniendo en cuenta a Antonio de Capmany como figura central, hemos constatado cómo su actitud lingüística ante las voces llegadas del país vecino varía enormemente: de alzarse como ilustrado admirador de lo francés, pasa a tener una postura moderada para, finalmente, mostrarse como un extremo nacionalista defensor a ultranza del purismo lingüístico. De hecho, Jiménez Ríos (2015: 50-51), también habla de esta evolución del pensamiento de Capmany: «de la tolerancia a la innovación pasa a la renuencia al cambio; un cambio, que académicos como Álvarez Cienfuegos veían con buenos ojos al no imponer ningún requisito a la admisión de nuevas voces» ${ }^{22}$.

${ }^{22}$ Ya Checa (1989: 150) declara que «el Capmany inicial, consciente del retraso español, era partidario de la introducción en nuestro país del pensamiento y cultura europeos, de ahí sus elogios para con Francia, aunque en sus últimas obras se muestra como un gran defensor de la lengua y cultura españolas, así como crítico con Francia». 
Precisamente, hemos visto cómo, acerca de la voz orfebre en su Diccionario francés-español(1805), en la prensa de la época, un lector critica a Capmany el hecho de que empleara el galicismo en lugar de otras voces como platero, orespe u orero, voces estas últimas ya desusadas entonces en nuestra lengua, según justifica el lexicógrafo. No situamos, pues, ante una discusión lingüística de interés: ¿en defensa de la pureza de la lengua, se debe priorizar el empleo de voces ya olvidadas? ¿Se ha de incluir una voz "extraña" que sea necesaria para aludir a un nuevo significado? Como recuerda Alvar (1992), la misma Real Academia Española, a partir de 1884, incluye paulatinamente todas esas palabras proscritas, que van tomando acomodo en su repertorio lexicográfico. Así, vemos que, a nivel normativo, se han ido modificando los criterios admisión y la adopción de extranjerismos ha obligado a cambiar las ideas sobre el purismo lingüístico.

Lo cierto es que, a propósito de Antonio de Capmany, numerosos especialistas coinciden en afirmar que se alza como una figura clave en el panorama de la lexicografía bilingüe a comienzos del siglo XIX. De hecho, según manifiesta Vidal (2011: 404), «si el espíritu del siglo XVIII está integrado por tres factores esenciales, que son el sentimiento histórico, el sentido crítico y el sentido enciclopédico, habremos de concluir que la obra de Capmany es producto genuino de aquel siglo».

\section{BIBLIOGRAFÍA CITADA}

ALVAR, M. (1992): «Los diccionarios académicos y el problema de los neologismos». En Reigosa, C. G. (coord.): El neologismo necesario. Madrid: Fundación EFE, 51-70 (en línea: <http://www.cervantesvirtual.com/obra-visor/losdiccionarios-acadmicos-y-el-problema-de-los-neologismos-

0/html/01099ca2-82b2-11df-acc7-002185ce6064_6.html>, consulta: 21 de febrero 2021).

Alvar EzQuerra, M. (2020): «Monfort, Luis (1780-1830)». En Alvar Ezquerra, M.: Biblioteca Virtual de la Filología Española (BVFE): directorio bibliográfico de gramáticas, diccionarios, obras de ortografía, ortología, prosodia, métrica, diálogos e historia de la lengua (en línea: <https://www.blog.bvfe.es/ en/ autor/10262-monfort-luis.html>, consulta: 3 de enero 2021). 
Álvarez de Miranda, P. (2013): «Nadie es purista». Rinconete, Blog del Centro Virtual Cervantes (en línea: <https://cvc.cervantes.es/el_rinconete/anteriores/octubre_13/15102013_01.htm>, consulta: 7 de enero 2021).

ANGLADA ARBOIX, E. (1997-1998): «Traducción y diccionario. Algunos neologismos de la química en el Nuevo diccionario francés-español (1805) de A. de Capmany». Revista de lexicografía, 4, 1-47.

CAPMANY, A. de (1776): Arte de traducir el idioma francés al castellano. Con el vocabulario lógico y figurado de la frase comparada de ambas lenguas. Madrid: Antonio Sancha.

CAPMANY, A. de (1778): Teatro histórico-crítico de la elocuencia española. Madrid: Antonio Sancha.

CAPMANY, A. de (1805): Nuevo diccionario francés-español. Madrid: Antonio Sancha.

Capmany, A. de (1808): Centinela contra franceses. Madrid: Gómez Fuentenegro y Compañía.

CAzorla VIVAS, C. (2002): Lexicografía bilingüe de los siglos XVIII y XIX con el español y el francés. Tesis doctoral. Universidad Complutense de Madrid.

CheCA Beltrán, J. (1988): «Una retórica enciclopedista del siglo XVIII: la Filosofía de la elocuencia, de Capmany». Revista de Literatura, 99, 61-90.

Checa Beltrán, J. (1989): «El elogio de la lengua española en Capmany». Revista de Filología Española, 69.1/2, 31-151.

CHeCA BeltráN, J. (1991): «Opiniones dieciochistas sobre la traducción como elemento enriquecedor o deformador de la propia lengua». En Donaire, M. L. y Lafarga, F. (eds.): Traducción y adaptación cultural España-Francia. Oviedo, Universidad de Oviedo, 593-602.

CORDE: Real Academia Española, Corpus diacrónico del español (en línea: $<$ http://corpus.rae.es/cordenet.html>, consulta: 4 de enero 2021).

CRESPo Hidalgo, J. (2008): «Estudio traductológico de Arte de traducir el francés al castellano. Antonio Capmany, edición de Barcelona, 1839». En Zaro, J. J. (ed.): Diez estudios sobre la traducción en la España del siglo XIX. Granada: Atrio, 15-54.

Hériz Ramón, A. L. de y San Vicente Santiago, F. (2012): «Traducción». En Zamorano Aguilar, A. (coord. y ed.): Reflexión lingüística y lengua en la España del siglo XIX: marcos, panoramas y nuevas aportaciones. München: Lincom, 197-228. 
JiMÉNEZ Ríos, E. (2015): «Recorrido histórico por las razones para la admisión de voces nuevas en la lengua y en el diccionario». Philologia Canariensia, 21, 45-80.

Lafarga, F. y Pegenaute, L. (eds.) (2009): Diccionario histórico de la traducción en España. Madrid: Arco Libros.

LÁZARo CARRETER, F. (1985): Las ideas linguïsticas en España en el siglo XVIII. Barcelona: Crítica (1 ${ }^{a}$ ed. 1949).

LESCASSE, M.-É. (2018): «¿Qué es el purismo?». Circula. Revue d'idéologies linguistiques, 8, 103-128.

LuDWIG, R. (2000-2001): «Desde el contacto hacia el conflicto lingüístico: el purismo en el español. Concepto, desarrollo histórico y significación actual». Boletín de Filología de la Universidad de Chile, 38, 167-196.

MARTINELL, E. (1984): «Posturas adoptadas ante los galicismos introducidos en el castellano en el siglo XVIII». Revista de Filología de la Universidad de La Laguna, 3, 101-123.

MURO, Á. (1892): Diccionario general de cocina. Madrid: Imprenta de José María Faniqueto.

NTLLE: Real Academia Española, Nuevo tesoro lexicográfico de la lengua española (en línea: <http://ntlle.rae.es/ntlle/SrvltGUILoginNtlle>, consulta: 8 de enero 2021).

PASTOR FUSTER, J. (1830): Biblioteca valenciana de los escritores que florecieron hasta nuestros días y de los que aún viven. Vol. II. Valencia: Impr. y librería de Ildefonso Mompié.

TORRES MARTíNEZ, M. (en prensa): «Recetas y léxico culinario en prensa española del siglo XIX». Boletín de Filología de la Universidad de Chile.

VIDAL DíEZ, M. (2011): «El Diccionario (1817) de A. de Capmany». En San Vicente, F. et al. (eds.). Ideolex. Estudios de Lexicografía e Ideología. Italy: Polimetrica International Scientific Publisher Monza, 403-418.

Yllera, A. y Ozaeta, M. R. (2002): Estudios de traducción. Francés-español. Madrid: UNED.

Marta TORRES MARTÍNEZ Universidad de Jaén matorma@ujaen.es https://orcid.org/0000-0002-7766-2315 